\title{
Skilled Worker Migration and Trade: Inequality and Welfare*
}

\author{
Spiros Bougheas \\ University of Nottingham \\ Doug Nelosn \\ Tulane University and University of Nottingham
}

September 1, 2008

\begin{abstract}
We develop a two-sector, two-country model where trade is driven by technological differences. Each country is populated by large number of heterogeneous workers distinguished by their level of skills. Given that one country has a technological advantage in the skilled intensive good when we allow for both trade and migration skilled workers migrate to that country. We analyze the consequences of this migration for both inequality and welfare for the source and the host country.
\end{abstract}

\footnotetext{
*Very Preliminary.
} 


\section{Introduction}

In its vast majority, the literature that considers the welfare aspects of migration in open economies has focused on cross-border movements of unskilled workers (e.g. Ethier, 1985, Wellisch and Walz, 1998 and Commander, Kangasniemi and Winters, 2003). In contrast, research on "brain drain" issues has been carried out using closed-economy frameworks (e.g. Bhagwati and Rodriguez, 1975 and Schiff, 1999). This trend reflects the fact that the latter literature attempted to address the concerns of less developed economies at a time when trade was significantly more restricted than nowadays. In recent years, commodity movements have been vastly liberalized and thus a complete appreciation of the welfare aspects of migration needs to take into account any effects due to changes in the terms of trade. In addition, as long as trade and factor movements take place between countries with democratically elected governments we also need to distiguish welfare outcomes from outcomes that are politically feasible.

To address these issues, we introduce migration of skilled workers in a two-country, two-sector trade model. The autarky version of the model follows the selection models by Borjas (1987) and Chiquiar and Hanson (2005) which in turn developed a mathematical framework for concepts first presented by Roy (1951). ${ }^{1}$ Migration is driven by a technology gap. While the two countries use the same technology in the primary sector, one country has a more efficient technology in the high-tech sector. The two countries have identical endowments of skills (human capital). ${ }^{2}$ In the primary sector worker productivity is independent of the level of skills. Skills however matter in the high-tech sector.

After we derive the equilibrium under autarky for each country, we solve for the free trade equilibrium. Next, we do not allow trade but we introduce migration. When migration is costless we arrive at a full integration equilibrium where everybody lives in the country that is technologically superior. We also derive the equilibrium when migration is costly and we find that when only skilled workers move the gap between the autarky prices widens. The intuition is that as skilled workers move away from the country that is technologically disadvantaged it increases the relative cost of producing the high tech-good and thus increases its relative price which in turn deteriorates the incomes of the producers of the primary commodity who also are the relatively poor. Migration has exactly the opposite effects on the technologically advanced country.

When we allow for both trade and migration we derive two main results. The first is that trade and migration are complements. Put differently, migration is higher under trade than under autarky. The second result is that welfare is higher when both trade and migration are allowed. More importantly, when we consider separately migrants, and the citizens of each country without including the migrants we find that migration and trade increase the welfare of each of these three groups.

Then we turn to the political economy implications of our model. When citizens are allowed to vote for whether or not to allow migration and on whether or not to compensate those who lose as a consequence of migration we find that the sequence of referenda can

\footnotetext{
${ }^{1}$ Bougheas and Riezman (2007), Davidso and Matusz (2006) and Davidson, Matusz and Nelson (2006) use the same framework to analyze a host of trade issues but not migration.

${ }^{2}$ See Rauch (1991) for an alternative model where countries differ in endowments.
} 
matter.

\section{The Model}

There are two countries $A$ and $B$ each populated by a continuum of workers of unit measure. Each worker is endowed with one unit of indivisible labor and some level of human capital $h$. In both countries human capital is uniformly distributed on the interval $[0,1]$. In each country there are two competitive sectors. Sector $X$ produces a hightech product while sector $Y$ produces a primary commodity. The productivity of workers depends on their level of human capital and their sector of employment. Let $z_{A X}(h)$ denote the productivity of a worker with human capital $h$ who works in country $A$ in sector $X$ (other types of employment are similarly defined). All four technologies are linear in $h$ :

$$
\begin{aligned}
& z_{A X}=h \\
& z_{B X}=k h ; \quad k>1 \\
& z_{A Y}=z_{B Y}=v ; \quad 0<v<1
\end{aligned}
$$

Both countries use the same technology to produce the primary commodity but country $B$ has a superior technology in sector $X$. In addition, the marginal return to human capital are higher in the high-tech sector.

All workers have identical Cobb-Douglas preferences given by

$$
U=X^{\alpha} Y^{\beta} ; \quad 0<\alpha, \beta<1 ; \quad \alpha+\beta=1
$$

Given that technologies are CRS and that all markets are competitive worker incomes equal their productivities and each workers spend a fraction $\alpha$ of her income on product $X$.

\subsection{Autarky}

Throughout we use good $X$ as the numeraire and let $p_{A}$ and $p_{B}$ denote the autarky prices in countries $A$ and $B$ respectively. In what follows we are going to concentrate our analysis on country $B$ since by setting $k=1$ we can obtain the corresponding solutions for country A.

Workers choose their sector of employment by comparing wages. A worker with human capital $h$ will receive income $k h$ if employed in sector $X$ while the same worker will receive income $p_{B} v$ if employed in sector $Y$. This implies that all workers with human capital higher than $h_{B} \equiv \frac{p_{B} v}{k}$ will be employed in the high-tech sector while workers with human capital below this threshold will be employed in the primary sector. Given our specification for preferences the equilibrium autarky price is proportional to the ratio of aggregate production in sector $X$ divided by the aggregate production in sector $Y$ :

$$
p_{B}=\frac{\beta}{\alpha} \frac{\int_{h_{B}}^{1} k h d h}{h_{B} v}
$$


The corresponding closed form solution for the autarky price is given by:

$$
p_{B}=\frac{k}{v} \sqrt{\frac{\beta}{2 \alpha+\beta}}
$$

Notice that the above solution implies that $p_{B}>p_{A}$ which follows from the fact that country $B$ has a superior technology for producing the high-tech product. It also follows that $h_{A}=h_{B}$.

\subsection{Trade}

When the two economies trade country $A$ exports the primary commodity $Y$ and country $B$ exports the high-tech product $X$. The world price $p^{T}$ lies between the two autarky prices and is given by

$$
p^{T}=\frac{\beta}{\alpha} \frac{\int_{h_{A}^{T}}^{1} h d h+\int_{h_{B}^{T}}^{1} k h d h}{\left(h_{A}^{T}+h_{B}^{T}\right) v}
$$

where $h_{A}^{T}=p^{T} v>h_{A}=h_{B}>\frac{p^{T} v}{k}=h_{B}^{T}$. The corresponding closed form solution for the world price is given by:

$$
p^{T}=\frac{\sqrt{k}}{v} \sqrt{\frac{\beta}{2 \alpha+\beta}}
$$

\subsection{Migration}

Suppose that the two economies do not trade but migration is allowed.

\subsubsection{Costless Migration}

Given that the two countries use the same technology to produce the primary commodity but country $B$ has a superior technology for producing the high-tech product every worker in country $A$ will emigrate in country $B$. The integration equilibrium price is equal to $p_{B}$, i.e. country $B$ 's autarky price.

\subsubsection{Costly migration}

Now suppose that migration entails a cost $\gamma$ measured in numeraire units. We are going to assume that this cost is sufficiently high so that workers in the primary sector do not wish to emigrate. ${ }^{3}$ Let $p_{A}^{M}$ and $p_{B}^{M}$ denote the two new autarky prices. The utility of a worker who is a citizen of country $A$, employed in sector $X$ and does not emigrate is equal to $(h)^{\alpha}\left(\frac{h}{p_{A}^{M}}\right)^{\beta}=h\left(p_{A}^{M}\right)^{-\beta} \cdot{ }^{4}$ If the same worker emigrates to country $B$ her new utility will

\footnotetext{
${ }^{3}$ When we introduce trade these workers will not have an incentive to emigrate. Thus, by restricting their movement in the absence of trade allows for clearer comparisons between the two cases.

${ }^{4}$ All utilities have beed divided by $\alpha^{\alpha} \beta^{\beta}$.
} 
be $(k h-\gamma)^{\alpha}\left(\frac{k h-\gamma}{p_{B}^{M}}\right)^{\beta}=(k h-\gamma)\left(p_{B}^{M}\right)^{-\beta}$. Then there exists a threshold level of human capital $h^{M}=\frac{\gamma\left(p_{B}^{M}\right)^{-\beta}}{k\left(p_{B}^{M}\right)^{-\beta}-\left(p_{A}^{M}\right)^{-\beta}}$ such that all workers with human capital above it and who initially were citizens in country $A$ emigrate to country $B$. Letting $h_{A}^{M}$ and $h_{B}^{M}$ denote the new threshold levels of human capital that separates those employed in sector $X$ from those employed in sector $Y$, in countries $A$ and $B$ respectively, the new autarky prices are given by the system of equations:

$$
p_{A}^{M}=\frac{\beta}{\alpha} \frac{\int_{h_{A}^{M}}^{h^{M}} h d h}{h_{A}^{M} v}
$$

and

$$
p_{B}^{M}=\frac{\beta}{\alpha} \frac{\int_{h^{M}}^{1}(k h-\gamma) d h+\int_{h_{B}^{M}}^{1} k h d h}{h_{B}^{M} v}
$$

Notice that the two equations need to be solved simultaneously since $h^{M}$ depends on both new autarky prices. This complication implies that it is not possible to derive closed-form solutions for the two prices. Nevertheless, the effect of migration is to increase the gap between the autarky prices, i.e. $p_{B}^{M}>p_{B}>p_{A}>p_{A}^{M}$. The intuition is that in country $A$ the old threshold level of human capital that separates those employed in sector $X$ from those employed in sector $Y$ is too high, given that only high ability workers have migrated while the corresponding threshold in country $B$ is too low. ${ }^{5}$

\section{Migration and Trade}

\subsection{Costless Migration}

When migration is costless it is optimal that the whole production of the high-tech product takes place in country $B$. In the absence of trade costs, the production location of the primary product is inconsequential. In the presence of trade costs it is optimal that all workers move to country $B$. In either case we have full integration. The full integration equilibrium price $p^{F I}$ is given as the solution of

$$
p^{F I}=\frac{\beta}{\alpha} \frac{\int_{h^{F I}}^{1} k h d h}{h^{F I} v}
$$

where $h^{F I}=\frac{p^{F I} v}{k}$. It is clear that the equilibrium world trade price and the critical threshold are the same as those for the autarky case for country $B$.

\footnotetext{
${ }^{5}$ Let $\mu$ denote the proportion of migrants. Given that both populations originally were of unit measure the new population of country $A$ is of measure $1-\mu$ and human capital is uniformly distributed on the interval $[0,1-\mu]$.
} 


\subsection{Costly Migration}

Once again suppose that migration entails a cost $\gamma$ measured in numeraire units. Given that when the two countries trade all workers face the same price, the only workers that move across borders are some of those workers who where citizens of country $A$ and employed in sector $X$ and now move to country $B$ and are employed in the same sector. For these workers their pre-migration income was equal to $h$ while their post-migration income is equal to $k h-\gamma$. This implies that there exists a threshold level of human capital $h^{*} \equiv \frac{\gamma}{k-1}$ such that all workers with human capital above it and who initially were citizens in country $A$ emigrate to country $B .{ }^{6}$ Letting $h_{A}^{*}$ and $h_{B}^{*}$ denote the new threshold levels of human capital that separates those employed in sector $X$ from those employed in sector $Y$, the new equilibrium price $p^{*}$ is given by

$$
p^{*}=\frac{\beta}{\alpha} \frac{\int_{h_{A}^{*}}^{h^{*}} h d h+\int_{h^{*}}^{1}(k h-\gamma) d h+\int_{h_{B}^{*}}^{1} k h d h}{\left(h_{A}^{*}+h_{B}^{*}\right) v}
$$

The corresponding closed form solution is:

$$
p^{*}=\frac{\sqrt{k}}{v} \sqrt{\frac{2 k-\gamma}{1+k}} \sqrt{\frac{\beta}{2 \alpha+\beta}}
$$

Given that $\sqrt{k}>\sqrt{\frac{2 k-\gamma}{1+k}}$ we have $p^{B}>p^{*}$. In addition, the inequality $\gamma<k-1$ implies that $p^{*}>p^{T}$ which in turn implies that $h_{B}^{*}>h_{B}^{T}$ and $h_{A}^{*}>h_{A}^{T}$. This is because migration has allowed a more efficient allocation of resources by moving high skilled workers to country $B$ which has a superior technology for producing the skill-intensive product $X$.

Comparing the threshold levels of human capital that separate those who emigrate from those who do not for the cases of migration without trade and migration with trade we get the following result

Proposition 1 Migration and trade are complements.

Proof The proposition follows from the inequality $p_{B}^{M}>p_{A}^{M}$ which ensures that $h^{*}<h^{M}$.

There is more migration under free trade. The intuition is that under trade prices converge which further boosts the incomes of the migrants and thus the incentive to migrate. Of course this is not a new result. Markusen (1983) and Razin and Sadka (1994) have, within more traditional trade modes, demonstrated the compementarity bertween trade and migration when countries differ in technologies.

\footnotetext{
${ }^{6}$ Notice that here is sufficient to compare incomes because the prices in the two countries are equal. Earlier we examined the case where there is no trade and therefore the prices in the two countries were different.
} 


\section{Welfare}

We measure group welfare as the sum of utilities of its individual members. We are focusing on three groups: The citizens of country $B$ (excluding migrants), the migrants and the citizens of country $A$ excluding migrants. Below we demonstrate that migration increases the welfare of all three groups and thus global welfare. ${ }^{7}$

\subsection{Citizens of Country B (excluding migrants)}

Those workers who were employed in the primary sector during the pre-migration period and are still employed in the same sector during the post-migration period are better off in the later period. This is because migration increases the price of the primary commodity and hence their income. For exactly the same reason those workers that are employed in the high-tech sector during both periods experience a loss in utility. In addition, the inequality $h_{B}^{*}>h_{B}^{T}$ implies that there are some workers who before migration were employed in the high-tech sector and after migration they moved to the primary sector. Among these workers some are better off and some are worse off. More specifically, there exists a threshold level of human capital, $\tilde{h}^{B}$, such that all workers with human capital below that level are better off after migration while all those workers with human capital above that level are worse off after migration.

Lemma 1 Migration increases the welfare of the citizens of country $B$.

Proof The post migration utility of an agent working in sector $X$ is equal to

$$
(k h)^{\alpha}\left(k \frac{h}{p}\right)^{\beta}=k h p^{-\beta}
$$

and the corresponding utility of an agent working in sector $Y$ is equal to

$$
(p v)^{\alpha} v^{\beta}=p^{\alpha} v
$$

Then, the post-migration welfare, $W^{B}$, of the citizens of country $B$ is given by

$$
\begin{aligned}
W^{B} & =\int_{0}^{\frac{p v}{k}} p^{\alpha} v d h+\int_{\frac{p v}{k}}^{1} k p^{-\beta} d h= \\
& =\frac{p^{1+\alpha} v^{2}}{k}+\frac{1}{2} k p^{-\beta}-\frac{1}{2} \frac{p^{2-\beta} v^{2}}{k}= \\
& =\frac{1}{2}\left[\frac{v^{2}}{k} p^{1+\alpha}+k p^{-(1-\alpha)}\right]
\end{aligned}
$$

Next consider the effect on welfare of a small change in the migration cost $\gamma$.

$$
\operatorname{sign}\left[\frac{d W^{B}}{d \gamma}\right]=\operatorname{sign}\left[\left((1+\alpha) \frac{v^{2}}{k} p^{\alpha}-\frac{(1-\alpha) k}{p^{2-\alpha}}\right) \frac{d p}{d \gamma}\right]
$$

\footnotetext{
${ }^{7}$ All utilities have beed divided by $\alpha^{\alpha} \beta^{\beta}$. In addition, by $p$ we denote the equilibrium price $p^{*}$ where for notational simplicity we have dropped the superscript when confusion can be avoided..
} 
Substituting for $p^{*}$ and rearranging we get

$$
\operatorname{sign}\left[\frac{d W^{B}}{d \gamma}\right]=\operatorname{sign}\left[\left(1-\frac{1+k}{2 k-\gamma}\right) \frac{d p}{d \gamma}\right]
$$

Given that $\gamma<k-1$ and $\frac{d p}{d \gamma}<0$ a decrease in migration costs will increase welfare.

\subsection{Migrants}

Lemma 2 Migration increases the welfare of the migrants.

Proof The pre-migration utility of a migrant is equal to

$$
h\left(p^{T}\right)^{-\beta}
$$

while the post-migration utility of a migrant is equal to

$$
h\left(p^{*}\right)^{-\beta} k
$$

Substituting for $p^{T}$ and $p^{*}$ we find that migration increases the welfare of migrants if and only if

$$
\frac{(\sqrt{1+k})^{1-\alpha}}{(\sqrt{2 k-\gamma})^{1-\alpha}} k>1
$$

As $\gamma \rightarrow 0$ the left-hand side of the above expression approaches

$$
\frac{(\sqrt{1+k})^{\frac{1-\alpha}{2}} k^{\frac{1+\alpha}{2}}}{2^{\frac{1-\alpha}{2}}}
$$

The above expression is increasing in $k$ and is equal to 1 for $k=1$ which, given that $k>1$, completes the proof.

\subsection{Citizens of Country A (excluding migrants)}

For exactly the same reasons as those analyzed for country $B$, those workers who were employed in the primary sector during the pre-migration period and are still employed in the same sector during the post-migration period are better off in the later period. Once more, the inequality $h_{A}^{*}>h_{A}^{T}$ implies that there are some workers who before migration were employed in the high-tech sector and after migration they moved to the primary sector. Among these workers some are better off and some are worse off. Again, there exists a threshold level of human capital, $\tilde{h}^{A}$, such that all workers with human capital below that level are better off after migration while all those workers with human capital above that level are worse off after migration.

Lemma 3 Migration increases the welfare of the citizens of country $A$ excluding the migrants. 
Proof The post migration utility of an agent working in sector $X$ is equal to

$$
h^{\alpha}\left(\frac{h}{p}\right)^{\beta}=k h p^{-\beta}
$$

and the corresponding utility of an agent working in sector $Y$ is equal to

$$
(p v)^{\alpha} v^{\beta}=p^{\alpha} v
$$

Then, the post-migration welfare, $W^{A}$, of the citizens of country $A$ is given by

$$
\begin{aligned}
W^{A} & =\int_{0}^{p v} p^{\alpha} v d h+\int_{p v}^{\frac{\gamma}{k-1}} p^{-\beta} d h= \\
& =p^{1+\alpha} v^{2}+\frac{1}{2} p^{-\beta}\left(\frac{\gamma}{k-1}\right)^{2}-\frac{1}{2} p^{2-\beta} v^{2}= \\
& =\frac{1}{2}\left[v^{2} p^{1+\alpha}+\frac{\gamma^{2}}{(k-1) p^{(1-\alpha)}}\right]
\end{aligned}
$$

Next consider the effect on welfare of a small change in the migration cost $\gamma$.

$$
\operatorname{sign}\left[\frac{d W^{A}}{d \gamma}\right]=\operatorname{sign}\left[\left\{\left((1+\alpha) v^{2} p^{\alpha}-\frac{(1-\alpha) k \gamma^{2}}{(k-1) p^{(2-\alpha)}}\right) \frac{d p}{d \gamma}\right\}+\frac{2 \gamma}{(k-1) p^{1-\alpha}}\right]
$$

Notice that a change in migration costs will affect the number of migrants and the last term captures the change in welfare as a result of the change in the size of the group. We know that a decrease in migration costs will increase the number of migrants and we know that their welfare will increase. Here, we need to concentrate only on the first term. Given that $\gamma<k-1, \frac{\gamma^{2}}{k-1}<1$ and the proof is completed by following the same steps as those used in the proof of proposition 1.

\subsection{Global Welfare}

The following proposition is a direct implication of the three lemmas.

Proposition 2 Migration increases global welfare.

\section{Political Economy}

The results of the previous section suggest that migration increases welfare in both countries even when migrants (who definitely gain) are ignored. This implies that the gains of those who benefit are more than sufficient to cover the losses of those workers who are worse off as a result of migration. However, for counties with democratically elected governments where majority voting decides key policy issues people might vote against migration and even if they decide to allow it losers might not be compensated. In this section, we show exactly under what conditions each of these outcomes materializes. In addition we show that the final outcome can also depend on the voting sequence. We begin by examining the possible outcomes of a referendum on migration ignoring, for the moment, any compensation policies. 


\subsection{Referendum on Migration}

We begin by considering the voting outcome in country $A$. The proportion of people who would vote in favor of migration, $\varphi_{A}^{M}$, is equal to

$$
\varphi_{A}^{M}=\tilde{h}^{A}+\left(1-\frac{\gamma}{k-1}\right)
$$

where the second term captures the votes of the migrants. The median voter's premigration utility is equal to $\tilde{h}^{A}\left(p^{T}\right)^{-\beta}$ while the same voter's post-migration utility is $\left(p^{*}\right)^{\alpha} v$; keeping in mind that in the pre-migration period is employed in sector $X$ and then moves to sector $Y$. Equating the two utilities, solving for the median voter's human capital and substituting in the above equality, we get

$$
\varphi_{A}^{M}=p^{T} v\left(\sqrt{\frac{2 k-\gamma}{1+\gamma}}\right)^{\alpha}+\left(1-\frac{\gamma}{k-1}\right)
$$

Next consider the voting outcome in country $B$. The proportion of people who would vote in favor of migration, $\varphi_{B}^{M}$, is equal to

$$
\varphi_{B}^{M}=\tilde{h}^{B}=\frac{\tilde{h}^{A}}{k}
$$

The proposition below follows from the inequality $\varphi_{B}^{M}<\varphi_{A}^{M}$ and the fact that both countries have to vote in favor of migration.

Proposition 3 In the absence of any compensation policy migration will take place if and only if $\varphi_{B}^{M}>0.5$.

Also, notice that a decline in migration costs increases the likelihood that the voting outcome will favor migration.

\subsection{Sequences of Referenda}

Suppose that citizens in each country they have the opportunity to vote on two referenda. In one referendum, as in the previous section, they vote on whether or not to allow migration (emigration in country $A$ and immigration in country $B$ ). In the other referendum they vote on whether or not there will be compensation for those who experience a loss in income as a result of migration. We demonstrate that the time sequence of the referenda matters for the voting outcomes. The reason is that the voting sequence affects the voting participation rates. In country $A$ if the migration referendum takes place first then the migrants might move to country $B$ before they had a chance to participate in the compensation referendum. Similarly, if the immigrants in country $B$, are allowed to vote, then they could affect the voting outcome on the compensation referendum when the latter takes place last. The following two propositions show exactly when the sequencing of votes matters. 
Proposition 4 Suppose that $\frac{1-\varphi_{A}^{M}}{\frac{\gamma}{k-1}}>0.50>1-\tilde{h}^{A}$. Then country $A$ will vote for compensation if and only if the migration referendum precedes the compensation referendum.

Proof If the migration referendum takes place first then the migrants will not vote on the compensation referendum. The first term in the above sequence of inequalities is equal to the proportion of workers who lose as a result of migration when migrants are excluded. It also captures the proportion of votes in favor of compensation when the compensation referendum takes place last. The last term is equal to the proportion of workers who lose as a result of migration when migrants are included. It also captures the proportion of votes in favor of compensation when the compensation referendum precedes the migration referendum.

For country $B$ the sequencing of votes could matter only when migrants are allowed to vote.

Proposition 5 Suppose that $1-\tilde{h}^{B}>0.5>\frac{1-\tilde{h}^{B}}{2-\frac{\gamma}{k-1}}$. Then country $B$ will vote for compensation if and only if the compensation referendum precedes the migration referendum.

Proof If the migration referendum takes place first then the migrants will vote on the compensation referendum. The first term in the above sequence of inequalities is equal to the proportion of workers who lose as a result of migration when migrants are excluded. It also captures the proportion of votes in favor of compensation when the compensation referendum takes place first. The last term is equal to the proportion of workers who lose as a result of migration when migrants are included. It also captures the proportion of votes in favor of compensation when the compensation referendum follows the migration referendum.

\section{Conclusion}

We have presented a two-country Roy type selection model of trade and skilled labor migration. Trade and migration are induced by differences in technologies. This framework can be easily extended to account for unskilled morker migration by having the two countries using different technologies for the production of the primary commodity. For that matter a general version can allow for migration of both types of workers which can be either in the same or in the opposite direction. ${ }^{8}$

\section{References}

\section{References}

[1] J. Bhagwati and C. Rodriguez, 1975. Welfare-theoretical analyses of the brain drain, Journal of Development Economics 2, 195-221

\footnotetext{
${ }^{8}$ Ishikawa (1996) offers a model of trade and migration, where the two countries differ in their endowments, and where both types of workers move in the same direction
} 
[2] G. Borjas, 1987. Self-selection and the earnings of immigrants, American Economic Review 77, 531-553

[3] S. Bougheas and R. Riezman, 2007. Trade and the distribution of human capital, Journal of International Economics 73, 421-433

[4] D. Chiquiar and G. Hanson, 2005. International migration, self-selection, and the distribution of wages: Evidence from Mexico and the United States, Journal of Political Economy 113, 239-281

[5] S. Commander, M. Kangasniemi and A. Winters, 2003. The brain drain: Curse or boon, IZA Discussion Paper No. 809

[6] C. Davidson and S. Matusz, 2006. Trade liberalization and compensation, International Economic Review 47, 723-747.

[7] C. Davidson, S. Matusz and D. Nelson, 2006. Can compensation save free trade, Journal of International Economics 71, 167-186

[8] W. Ethier, 1985. International trade and migration, American Economic Review 75, 691-707

[9] J. Ishikawa, 1996. Scale economies in factor supplies, international trade, and migration, Canadian Journal of Economics 29, 573-594

[10] J. Markusen, 1983. Factor movements and commodity trade as complements, Journal of International Economics 14, 341-356

[11] J. Rauch, 1991. Reconciling the pattern of trade with the pattern of migration, American Economic Review 81, 775-796

[12] A. Razin and E. Sadka, 1994. International migration and international trade, in M. Rosenzweig and O. Stark (eds.) Handbook of Population and Family Economics, Vol. 1, North-Holland Publishers

[13] A. Roy, 1951. Some thoughts on the distribution of earnings, Oxford Economic Papers $3,135-146$

[14] M. Schiff, 1999. Trade, migration and welfare: The impact of social capital, World Bank Policy Research Working Paper 2044

[15] D. Wellisch and U. Walz, 1998. Why do rich countries prefer free trade over free migration? The role of the modern welfare state, European Economic Review 42, $1595-1612$ 